Check for updates

Cite this: RSC Adv., 2018, 8, 18038

Received 7th March 2018

Accepted 11th May 2018

DOI: $10.1039 / \mathrm{c} 8 \mathrm{ra02033g}$

rsc.li/rsc-advances

\title{
Examining the effect of hydroxyl groups on the thermal properties of polybenzoxazines: using molecular design and Monte Carlo simulation
}

\begin{abstract}
Kan Zhang, ${ }^{a}$ Lu Han, $^{\mathrm{b}}$ Yijing Nie, ${ }^{* a}$ Matthew Louis Szigeti ${ }^{\mathrm{b}}$ and Hatsuo Ishida (iD *b
The influence of methylol and phenolic hydroxyl on the thermal properties of polybenzoxazines has been studied using two monofunctional benzoxazine monomers synthesized from para methylol-/ethyl- phenol, aniline and paraformaldehyde. The chemical structures of the synthesized monomers are confirmed by ${ }^{1} \mathrm{H}$ nuclear magnetic resonance (NMR), ${ }^{13} \mathrm{C} N M R$ and Fourier transform infrared spectroscopy (FT-IR). Polymerizations are monitored by differential scanning calorimetry (DSC). The glass transition temperature $\left(T_{\mathrm{g}}\right)$ of each polybenzoxazine is measured by DSC as well as dynamic mechanical analysis (DMA), indicating the greatly increased $T_{\mathrm{g}}$ via incorporation of methylol functionality into benzoxazine moiety. Monte Carlo simulations are also applied to further investigate the underlying structure-property relationship between intermolecular hydrogen-bonding network originating from different types of hydroxyl groups and thermal properties of polybenzoxazines. The agreement between the experimental and simulation results provide us with a fundamental understanding of the designing roles in highly thermally stable polybenzoxazines.
\end{abstract}

\section{Introduction}

In recent years, needs for development of polymers with highly thermally stable properties have increased drastically due to technological advancements that require materials for use in harsher environments. Polybenzoxazines are a class of thermosetting phenolic resins that gained great interest because of their unusual set of competitive properties. ${ }^{1-6}$ They combine various outstanding properties of high performance thermosets like high thermal stability, ${ }^{7}$ high char yield, ${ }^{8}$ high glass transition temperature $\left(T_{\mathrm{g}}\right),{ }^{9}$ near-zero volumetric change during polymerization, ${ }^{10}$ good mechanical ${ }^{11}$ and dielectric properties, ${ }^{12,13}$ low water absorption ${ }^{14}$ and low flammability. ${ }^{15}$ The most attractive characteristic of polybenzoxazines is their extraordinarily rich molecular design flexibility and versatility in molecular structure. Thus, polybenzoxazine can satisfy specific requirements for different applications such as high temperature resistant adhesives, coatings, membranes and aerospace materials. For example, the thermal stability of polybenzoxazines can be achieved by incorporation of various functionalities such as amide, ${ }^{16,17}$ imide ${ }^{17,18}$ allyl, ${ }^{19,20}$ nitrile ${ }^{21}$ and furfury ${ }^{22}$ or increasing the number of oxazine rings in molecular backbone. ${ }^{23}$

${ }^{a}$ School of Materials Science and Engineering, Jiangsu University, Zhenjiang 212013, China.E-mail: nieyijing@ujs.edu.cn

${ }^{b}$ Department of Macromolecular Science and Engineering, Case Western Reserve University, Cleveland, OH, 44106, USA. E-mail: hxi3@cwru.edu
Benzoxazines containing hydroxyl group have been extensively studied due to their lower polymerization temperature and the modifiable character of hydroxyl functionality. ${ }^{24-27}$ Among these hydroxylated compounds, methylol functional benzoxazines have been reported as flexible precursors for chemical modification and their improved polymerization behavior and polymer properties. ${ }^{28,29}$ For example, a methacryloyl-benzoxazine-containing monomer from methylolfunctional benzoxazine was synthesized and its photopolymerization behavior as well as thermal polymerization was studied by Jin et al..$^{28}$ Besides, the hydrogen-bonding interactions and polymerization mechanism of methylol functional benzoxazine isomers have been systematically investigated..$^{30-33}$ It has been found that intermolecular hydrogen-bonding exists in para-methylol functional benzoxazines. However, intramolecular hydrogen-bonding system is present only in the ortho-isomer. $^{32}$ In addition, both condensation reaction between the methylol and phenyl groups, in a manner similar to the traditional phenolic resins, and the usual cationic ringopening polymerization of the oxazine group during thermal treatment of ortho-methylol functional benzoxazine were found to occur. ${ }^{33}$ Unlike smart reactions reported for ortho-functional benzoxazines that further undergo structural transformation forming benzoxazole structure at elevated temperatures, only phenolic moieties can be formed for para-isomer upon heating. Despite lack of the structural transformation unique to the ortho-isomers, it is worth noticing that excellent thermal stability of the polybenzoxazines derived from para-methylol functional benzoxazine monomers compared with other 
<smiles>OCc1ccc(O)cc1</smiles><smiles>Nc1ccccc1</smiles><smiles></smiles><smiles></smiles><smiles>OCc1ccc2c(c1)CN(c1ccccc1)CO2</smiles><smiles>CCc1ccc(O)cc1</smiles>

\section{$+$}<smiles>Nc1ccccc1</smiles>

$\left.+\frac{2}{\mathrm{n}}+\mathrm{CH}_{2} \mathrm{O}\right)_{\mathrm{n}}$
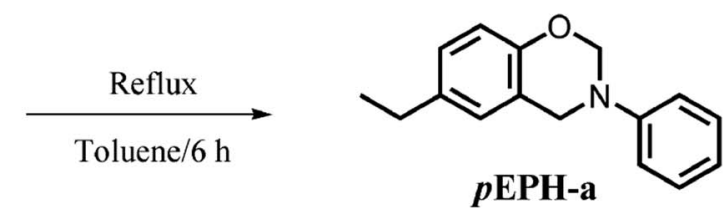

Scheme 1 Synthesis of methylol and ethyl functional benzoxazine monomers.

traditional polybenzoxazines based on non-hydroxyl benzoxazine monomers can be obtained. It is hypothesized that the existence of additional hydroxyl from methylol groups in polybenzoxazine network is the key factor causing their outstanding thermal properties.

Dynamic Monte Carlo simulations are usually applied to investigate microscopic structural changes or segmental dynamics, such as polymer crystallization, ${ }^{34-36}$ structural relaxation $^{37,38}$ and glass transition..$^{39,40}$ Previously, the correlation between dynamic heterogeneity and conformational transition during glass transition ${ }^{41}$ has been revealed by using dynamic Monte Carlo simulations. Such conformational change is the key factor controlling the effect of chain topology on dynamic heterogeneity and fragility. ${ }^{42,43}$ In addition, we also demonstrated that local segmental density and interfacial interaction are the key factors controlling the distribution of local $T_{\mathrm{g}} \mathrm{S}$ in ultrathin polymer films.$^{44}$ In short, many experimental findings can be theoretically supported, and, more importantly, underlying molecular mechanisms can be unearthed based on molecular simulations where experimental verification is difficult.

This work forms part of our ongoing research into examining and understanding the role of hydroxyl functionalities on improving the thermal properties of polybenzoxazines. Here, we synthesize two benzoxazine monomers, $p$ HBA-a (a hydroxylcontaining benzoxazine) and $p \mathrm{EPH}-\mathrm{a}$ (ethyl-functional benzoxazine) as shown in Scheme 1 to investigate the existence of different roles of hydroxyl on the thermal properties of polybenzoxazines. $p \mathrm{EPH}$-a is designed as a control by replacing the hydroxyl in $p$ HBA-a by methyl for comparison. We correlate analytical measurements carried out on very pure benzoxazine samples with Monte Carlo simulations in order to better understand the underlying structure-property relationship between different types of hydroxyl interactions and thermal properties of polybenzoxazines.

\section{Experimental}

\section{Materials}

4-Hydroxybenzyl alcohol ( $p \mathrm{HBA})$ (98\%), 4-ethylphenol ( $p \mathrm{EPH})$ $(98 \%)$, aniline, and paraformaldehyde (96\%) were used as received from Sigma-Aldrich. Toluene, ethyl acetate, hexane, chloroform, sodium hydroxide, and sodium sulfate were obtained from Fisher Scientific and used as received.

\section{Synthesis of (3-phenyl-3,4-dihydro-2H-benzo[e][1,3]oxazin-6- yl)methanol (abbreviated as $p$ HBA-a)}

Into a $50 \mathrm{~mL}$ round flask were added $20 \mathrm{~mL}$ of toluene, aniline (1.4 g, $15 \mathrm{mmol}), p$ HBA $(1.83 \mathrm{~g}, 15 \mathrm{mmol})$, and paraformaldehyde $(0.96 \mathrm{~g}, 30 \mathrm{mmol})$. The mixture was refluxed for $6 \mathrm{~h}$. Then the product was concentrated using a rotary evaporator and redissolved in chloroform followed by base-wash using $1 \mathrm{~N} \mathrm{NaOH}$ aqueous solution three times and subsequent wash with deionized water. The chloroform solution was dried over sodium sulfate anhydrous and recrystallized from chloroform to yield white crystals (yield: $75 \%$ ). ${ }^{1} \mathrm{H}$ NMR $\left(600 \mathrm{MHz}, \mathrm{DMSO}-d_{6}, 25{ }^{\circ} \mathrm{C}\right) \delta$, ppm: $4.34\left(\mathrm{~d}, 2 \mathrm{H},-\mathrm{CH}_{2}-\mathrm{OH},\right)$, $4.62\left(\mathrm{~s}, 2 \mathrm{H}, \mathrm{Ar}-\mathrm{CH}_{2}-\mathrm{N}\right.$, oxazine), $5.00(\mathrm{t}, 1 \mathrm{H},-\mathrm{OH}), 5.40(\mathrm{~s}, 2 \mathrm{H}$, O- $\mathrm{CH}_{2}-\mathrm{N}$, oxazine), 6.65-7.21 (m, 8H, Ar). FT-IR spectra $(\mathrm{KBr}), \mathrm{cm}^{-1}: 3250$ (stretching of $\mathrm{OH}$ of methylol), 1497 (stretching of trisubstituted benzene ring), 1236 (Ar-O-C asymmetric stretching), 944 (oxazine ring related mode). Anal. calcd for $\mathrm{C}_{15} \mathrm{H}_{15} \mathrm{NO}_{2}$ : C, $74.69 \% ; \mathrm{H}, 6.22 \% ; \mathrm{N}, 5.84 \%$. Found: C, $74.13 \%$; $\mathrm{H}, 6.37 \%$; N, $5.69 \%$.

\section{Synthesis of 6-ethyl-3-phenyl-3,4-dihydro-2H-benzo $[e][1,3]$ oxazine (abbreviated as $\boldsymbol{p}$ EPH-a)}

Into a $50 \mathrm{~mL}$ round flask were added $20 \mathrm{~mL}$ of toluene, aniline (1.4 g, $15 \mathrm{mmol}), p \mathrm{EPH}(1.86 \mathrm{~g}, 15 \mathrm{mmol})$, and paraformaldehyde $(0.96 \mathrm{~g}, 30 \mathrm{mmol})$. The mixture was refluxed for $6 \mathrm{~h}$. Then the product was cooled to room temperature and washed with $1 \mathrm{~N}$ $\mathrm{NaOH}$ solution and then water to eliminate the unreacted residual starting materials and byproducts. The solution was dried over sodium sulfate anhydrous and followed by fractionating with column chromatography (eluent: hexanes and ethyl acetate, in a volume ration of $4: 1$ ) to obtain final products (yield: $58 \%$ ). ${ }^{1} \mathrm{H}$ $\operatorname{NMR}\left(600 \mathrm{MHz}, \mathrm{CDCl}_{3}, 25^{\circ} \mathrm{C}\right) \delta$, ppm: $1.18\left(\mathrm{~m}, 3 \mathrm{H},-\mathrm{CH}_{3}\right), 2.55$ (q, $\left.2 \mathrm{H},-\mathrm{CH}_{2}\right), 4.61\left(\mathrm{~s}, 2 \mathrm{H}, \mathrm{Ar}-\mathrm{CH}_{2}-\mathrm{N}\right.$, oxazine), $5.33\left(\mathrm{~s}, 2 \mathrm{H}, \mathrm{O}-\mathrm{CH}_{2}-\mathrm{N}\right.$, oxazine), 6.64-7.25 (m, 8H, Ar). FT-IR spectra (KBr), $\mathrm{cm}^{-1}: 1499$ (stretching of trisubstituted benzene ring), 1228 (Ar-O-C asymmetric stretching), 949 (oxazine ring related mode). Anal. calcd for 
$\mathrm{C}_{15} \mathrm{H}_{15} \mathrm{NO}_{2}: \mathrm{C}, 80.30 \% ; \mathrm{H}, 7.16 \% ; \mathrm{N}, 5.85 \%$. Found: $\mathrm{C}, 80.09 \% ; \mathrm{H}$, $7.22 \%$; N, $5.78 \%$.

\section{Polymerization of benzoxazine monomers}

Each benzoxazine monomer was polymerized using different polymerization cycles. Polymerizations of $p \mathrm{HBA}-\mathrm{a}$ was carried out in an oven by heating at 160, 180, 200 and $220^{\circ} \mathrm{C}$ for $2 \mathrm{~h}$ each step, thus obtaining poly( $p$ HBA-a). In addition, polymerization of $p \mathrm{EPH}-\mathrm{a}$ was done by heating at 160, 180, 200, 220, 240 and $260{ }^{\circ} \mathrm{C}$ for $2 \mathrm{~h}$ each step, thus forming poly $(p \mathrm{EPH}-\mathrm{a})$.

Characterization. Varian Oxford AS600 (600 MHz) nuclear magnetic resonance (NMR) spectrometer was used to obtain ${ }^{1} \mathrm{H}$ and ${ }^{13} \mathrm{C}$ NMR spectra using the number of transient of 64 and 1024, respectively. ${ }^{1} \mathrm{H}-{ }^{1} \mathrm{H}$ nuclear Overhauser effect spectroscopy (NOESY) was conducted on Bruker AVANCE II $400 \mathrm{MHz}$ NMR. A Bomem Michelson MB100 Fourier transform infrared (FT-IR) spectrophotometer was used to obtain FT-IR spectra. The spectrophotometer was equipped with a deuterated triglycine sulfate (DTGS) detector and a dry air purge unit. Sixty four scans were coadded at a resolution of $4 \mathrm{~cm}^{-1}$ in the frequency range of 4000-400 $\mathrm{cm}^{-1}$. All benzoxazine monomers were finely ground with potassium bromide powder and pressed into a disk and the spectrum was taken as the transmission mode. A TA Instruments differential scanning calorimeter (DSC) model 2920 was used with a temperature ramp rate of $10^{\circ} \mathrm{C} \mathrm{min}{ }^{-1}$ and a nitrogen flow rate of $60 \mathrm{~mL} \mathrm{~min}^{-1}$ for all tests of DSC study. All samples were sealed in hermetic aluminum pans with lids. Viscosity was tested by Anton Paar GmbH Rheometer MCR 301 with constant shear rate at $10 \mathrm{~s}^{-1}$ with a temperature ramp rate of $5{ }^{\circ} \mathrm{C} \mathrm{min}^{-1}$. Dynamic mechanical analysis (DMA) was conducted on a TA Instruments Model Q800 DMA applying controlled strain tension mode with amplitude of $10 \mu \mathrm{m}$ and a temperature ramp rate of $3{ }^{\circ} \mathrm{C} \mathrm{min}^{-1}$. Strain sweep was first performed to determine the linear viscoelastic limit. Thermogravimetric analyses (TGA) were performed on a TA Instruments Q500 thermogravimetric analyzer that was purged with nitrogen at a flow rate of $40 \mathrm{~mL} \mathrm{~min}^{-1}$. A heating rate of $10{ }^{\circ} \mathrm{C} \min ^{-1}$ was applied.

Simulation details. Dynamic Monte Carlo simulations were carried out on lattice space. First, a lattice box containing $30 \times$ $30 \times 30$ cubic lattice cells with periodic boundary conditions was set up. Then, 390 model chains, each containing 60 segments, were regularly put into the simulation box. In the lattice space, one lattice site could be only occupied by one segment, and double occupations were not allowed due to the volume exclusion of polymer chains. In this condition, the polymer volume fraction was 0.867 , and the remaining vacancy lattice sites were treated as free volume for the trial moves of polymer chains. The bonds could be oriented either along lattice axes or along diagonals, and therefore the coordination number of each segment was 26. During chain movements, a segment could jump from an occupied site into a neighboring unoccupied site.

The conventional Metropolis sampling algorithm is used to decide whether a motion can be accepted with the potential energy penalty by eqn (1):

$$
E=c E_{\mathrm{c}}+l E_{\mathrm{LJ}}+b E_{\mathrm{b}}
$$

where $E_{\mathrm{c}}$ is the bending energy for two consecutive bonds along the chain, reflecting the chain semiflexibility. ${ }^{34}$ Besides, $E_{\mathrm{LJ}}=4 \varepsilon\left[\left(\frac{\sigma}{r}\right)^{12}-\left(\frac{\sigma}{r}\right)^{6}\right]$ is the Lennard-Jones potential for nonbonded segments $(\varepsilon$ is the characteristic energy well of the potential, $\sigma$ is the lattice spacing in consideration of the excluded volume, and $r$ is the distance between two non-bonded segments), $E_{\mathrm{b}}$ is the mixing-interaction energy for one nearestneighbor pair of hydroxyl groups, reflecting the hydrogenbonding interactions, $\mathrm{c}$ is the net number of non-collinear connection pairs of bonds along the chain, $l$ is the net number of Lennard-Jones interaction pairs between nonbonded segments within the cut-off distance, and b is the net change of the nearest-neighbor hydroxyl pairs. In the current simulations, $4 \varepsilon / E_{\mathrm{c}}$ is fixed at $2, E_{\mathrm{b}} / E_{\mathrm{c}}$ is set to $-1, \sigma$ is 1 lattice site, the cut-off distance for the Lennard-Jones potential is 3 lattice sites, and $k T / E_{\mathrm{c}}$ ( $k$ is the Boltzmann's constant and $T$ is the temperature) represents the reduced system temperature (abbreviated as $T^{*}$ ). The initial chains with regular arrangements were relaxed for $10^{6} \mathrm{MC}$ cycles (one MC cycle represents the step when all segments have a move trial on average) to obtain an equilibrium melt state at $T^{*}=8.0$. Subsequently, the system was cooled gradually from $T^{*}=8.0$ to $T^{*}=0.05$ at a cooling rate of 0.01 unit of $T^{*}$ per $100 \mathrm{MC}$ cycles.

\section{Result and discussion}

\section{Synthesis of benzoxazine monomers}

Monofunctional benzoxazine monomer containing methylol functionality was successfully synthesized using a primary amine (aniline), formaldehyde, and 4-hydroxybenzyl alcohol ( $p$ HBA). In addition, a counterpart, $p \mathrm{EPH}-\mathrm{a}$, has also been designed. $p \mathrm{EPH}-\mathrm{a}$ is a benzoxazine compound with para functionality of ethyl group, while the functionality is methylol for $p$ HBA-a at the same position. The synthesis routes involving structure of the reactants used, and final benzoxazine monomers are shown in Scheme 1.

The chemical structures of $p \mathrm{HBA}-\mathrm{a}$ and $p \mathrm{EPH}-\mathrm{a}$ are confirmed by ${ }^{1} \mathrm{H}$ NMR, ${ }^{13} \mathrm{C}$ NMR, FT-IR and elemental analysis. Fig. 1 shows the ${ }^{1} \mathrm{H}$ NMR spectra of $p$ HBA-a and $p$ EPH-a. The characteristic resonances ${ }^{2}$ attributed to the oxazine ring structure, $\mathrm{Ar}-\mathrm{CH}_{2}-\mathrm{N}-$ and $-\mathrm{O}-\mathrm{CH}_{2}-\mathrm{N}-$ for $p \mathrm{HBA}-\mathrm{a}$ are observed at 4.60 and $5.40 \mathrm{ppm}$, respectively. The corresponding resonances for $p \mathrm{EPH}$-a are observed at 4.61 and $5.33 \mathrm{ppm}$, respectively. The ${ }^{1} \mathrm{H}$ NMR spectrum also indicates the presence of the methylol group $\left(-\mathrm{CH}_{2} \mathrm{OH}\right)$ in $p \mathrm{HBA}-\mathrm{a}$ based on the observation of the resonances of $-\mathrm{CH}_{2}-\mathrm{O}$ and hydroxyl attached to a methylol group at 4.34 and $5.00 \mathrm{ppm}$, respectively. Moreover, the resonances due to the presence of ethyl group in $p \mathrm{EPH}-\mathrm{a}$ are observed at 1.18 and $2.55 \mathrm{ppm}$.

${ }^{13} \mathrm{C}$ NMR analyses were also performed to further confirm the structures of $p \mathrm{HBA}-\mathrm{a}$ and $p \mathrm{EPH}-\mathrm{a}$. The spectra are shown in Fig. 2. The two singlets at 49.70 and 79.85 ppm for $p H B A-a$ and 50.49 and $79.33 \mathrm{ppm}$ for $p \mathrm{EPH}-\mathrm{a}$ are typical carbon resonances ${ }^{2}$ of $\mathrm{Ar}-\mathrm{CH}_{2}-\mathrm{N}-$ and $-\mathrm{O}-\mathrm{CH}_{2}-\mathrm{N}-$ of the oxazine ring, respectively. 


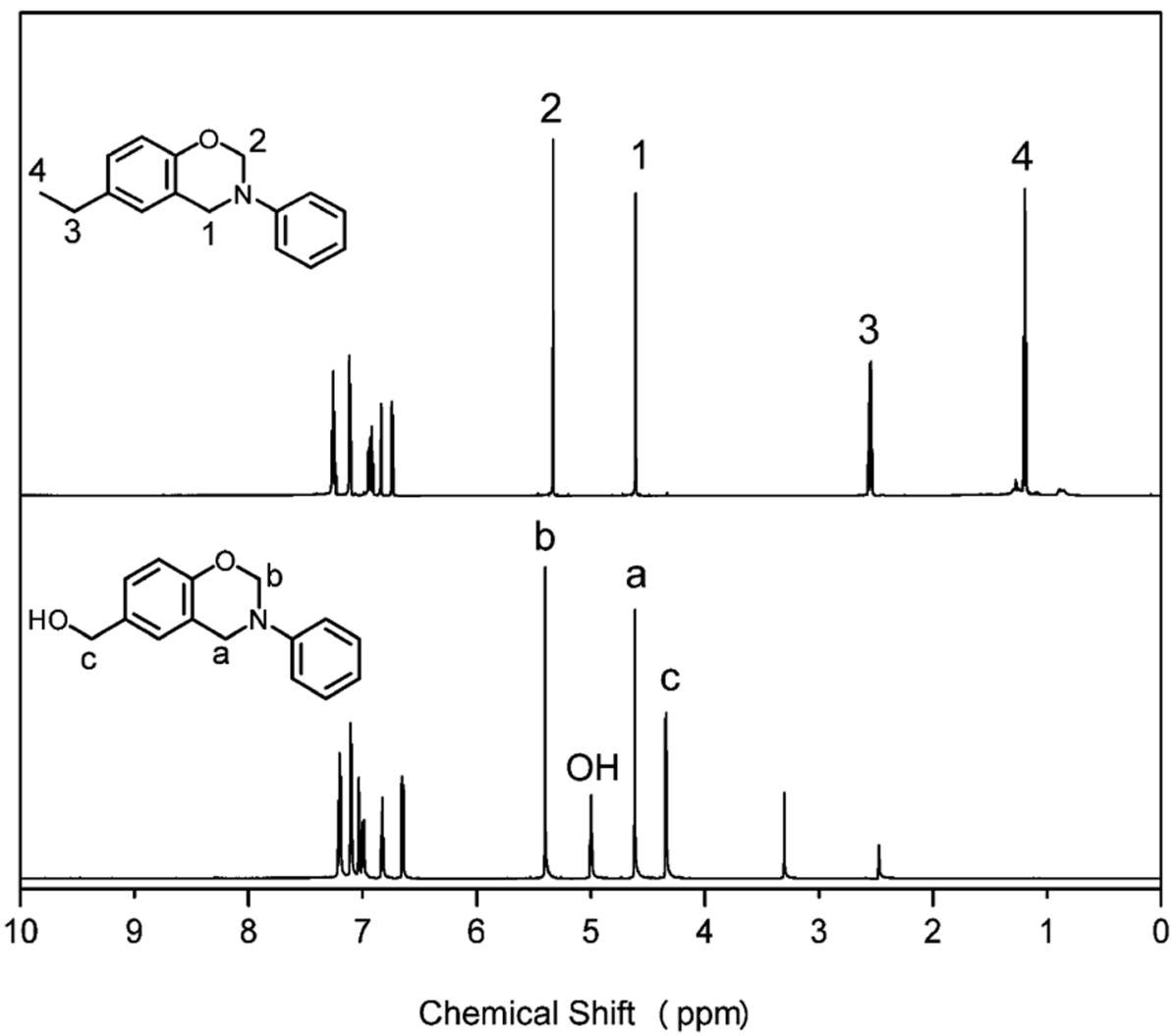

Fig. $1{ }^{1} \mathrm{H}$ NMR spectra of $p \mathrm{HBA}-\mathrm{a}$ (in DMSO- $d_{6}$ ) and $p \mathrm{EPH}-\mathrm{a}$ (in $\mathrm{CDCl}_{3}$ ).

The resonance at $63.25 \mathrm{ppm}$ is assigned to the carbon of methylol group for $p \mathrm{HBA}-\mathrm{a}$ while the resonances at 15.76 and 28.05 ppm are due to the presence of ethyl in $p \mathrm{EPH}-\mathrm{a}$.

FT-IR spectra of $p \mathrm{HBA}-\mathrm{a}$ and $p \mathrm{EPH}-\mathrm{a}$ using the $\mathrm{KBr}$ pellet method are shown in Fig. 3. The FT-IR spectrum of $p$ HBAa shows a broad band around $3250 \mathrm{~cm}^{-1}$, corresponding to the stretching vibrational mode of the $-\mathrm{OH}$ group. Besides, characteristic bands of asymmetrically trisubstituted benzene ring are observed at 1497 and $1499 \mathrm{~cm}^{-1}$ for $p \mathrm{HBA}-\mathrm{a}$ and $p \mathrm{EPH}-$ a, respectively, confirming the presence of functionalities as a constitutive part of both benzoxazine monomers. In addition, the existence of a benzoxazine ring aromatic ether in the monomers is indicated by the bands centered at 1236 and $1228 \mathrm{~cm}^{-1}$ for $p \mathrm{HBA}-\mathrm{a}$ and $p \mathrm{EPH}-\mathrm{a}$, respectively, which is due to the $\mathrm{C}-\mathrm{O}-\mathrm{C}$ asymmetric stretching modes. ${ }^{45}$ Furthermore, the characteristic bands at 944 and $949 \mathrm{~cm}^{-1}$ for $p \mathrm{HBA}-\mathrm{a}$ and $p$ EPH-a, which are mainly related to the oxazine ring, the vibration of $\mathrm{O}-\mathrm{C}_{2}$ vibration with a minor contribution from the phenolic ring ( $\mathrm{C}-\mathrm{H}$ out of plane bending, $\mathrm{C}-\mathrm{C}-\mathrm{C}-\mathrm{C}$ torsion). ${ }^{\mathbf{4 6}}$ Moreover, elemental analysis was also performed and the excellent agreement between the calculated and observed data for the purified sample, showing that the targeted compounds, $p \mathrm{HBA}-\mathrm{a}$ and $p \mathrm{EPH}-\mathrm{a}$ were obtained in high purity. This last result along with all the previous spectroscopic information are consistent with the successful synthesis of the target compounds.

\section{D ${ }^{1} \mathrm{H}-{ }^{1} \mathrm{H}$ NMR NOESY analysis of benzoxazine monomer}

Prior to this study, the presence of hydrogen bonding systems in methylol functional benzoxazines has been investigated by 1D ${ }^{1} \mathrm{H}$ NMR, and only intermolecular hydrogen bonding was observed in $p \mathrm{HBA}-\mathrm{a}$ due to the existence of the clear dependence of the $\mathrm{OH}$ chemical shift upon concentration. ${ }^{32}$ Herein, $2 \mathrm{D}{ }^{1} \mathrm{H}^{-1}{ }^{1} \mathrm{H}$ NOESY NMR of $p \mathrm{HBA}-\mathrm{a}$ in DMSO- $d_{6}$ has been performed and its results are shown in Fig. 4. The $\mathrm{OH}$ proton from methylol interacts through space with no other protons in the same molecule, further indicating no intramolecular hydrogen bonding is formed in $p$ HBA-a. Therefore, only intermolecular hydrogen bonds could be formed through methylol-methylol or methylol-oxazine ring interaction in $p$ HBA-a, resulting in stronger driving force for crystal formation and higher melting temperature.

\section{Polymerization behavior of benzoxazine monomer}

DSC was used to study the polymerization behavior of $p \mathrm{HBA}$ a and $p$ EPH-a as shown in Fig. 5. The thermograms show that the ring-opening polymerization of $p \mathrm{EPH}-\mathrm{a}$ started at $250{ }^{\circ} \mathrm{C}$ with its maximum centered at $267{ }^{\circ} \mathrm{C}$. However, the onset of polymerization is shifted in the presence of methylol group to as low as $175{ }^{\circ} \mathrm{C}$ for $p \mathrm{HBA}-\mathrm{a}$. In addition, the peak is broadened and the maximum is also reduced to $216{ }^{\circ} \mathrm{C}$. In general, electron-withdrawing substituents lead to a more acidic phenol 


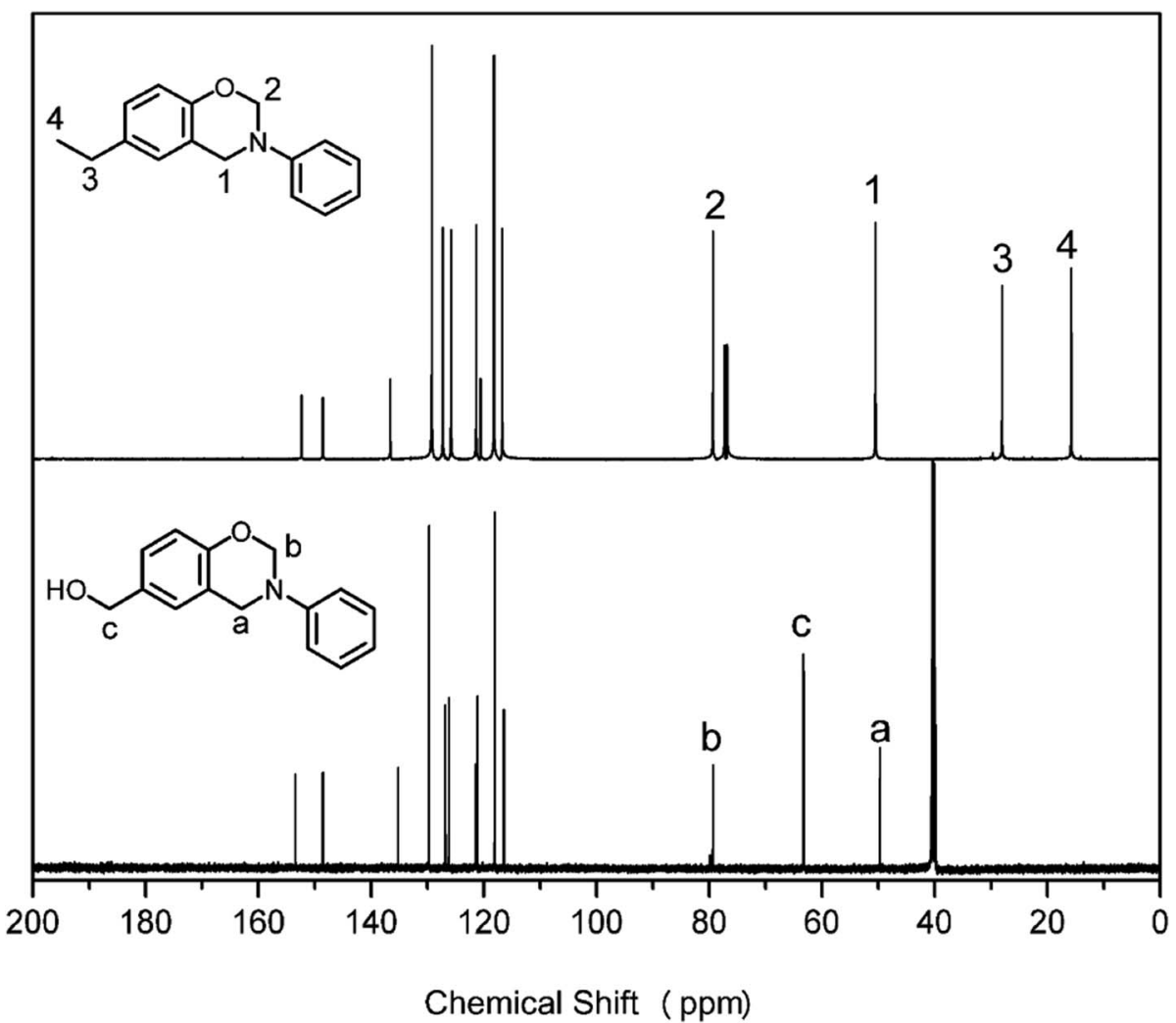

Fig. $2{ }^{13} \mathrm{C}$ NMR spectra of $p \mathrm{HBA}-\mathrm{a}$ (in DMSO- $d_{6}$ ) and $p \mathrm{EPH}-\mathrm{a}$ (in $\mathrm{CDCl}_{3}$ ).

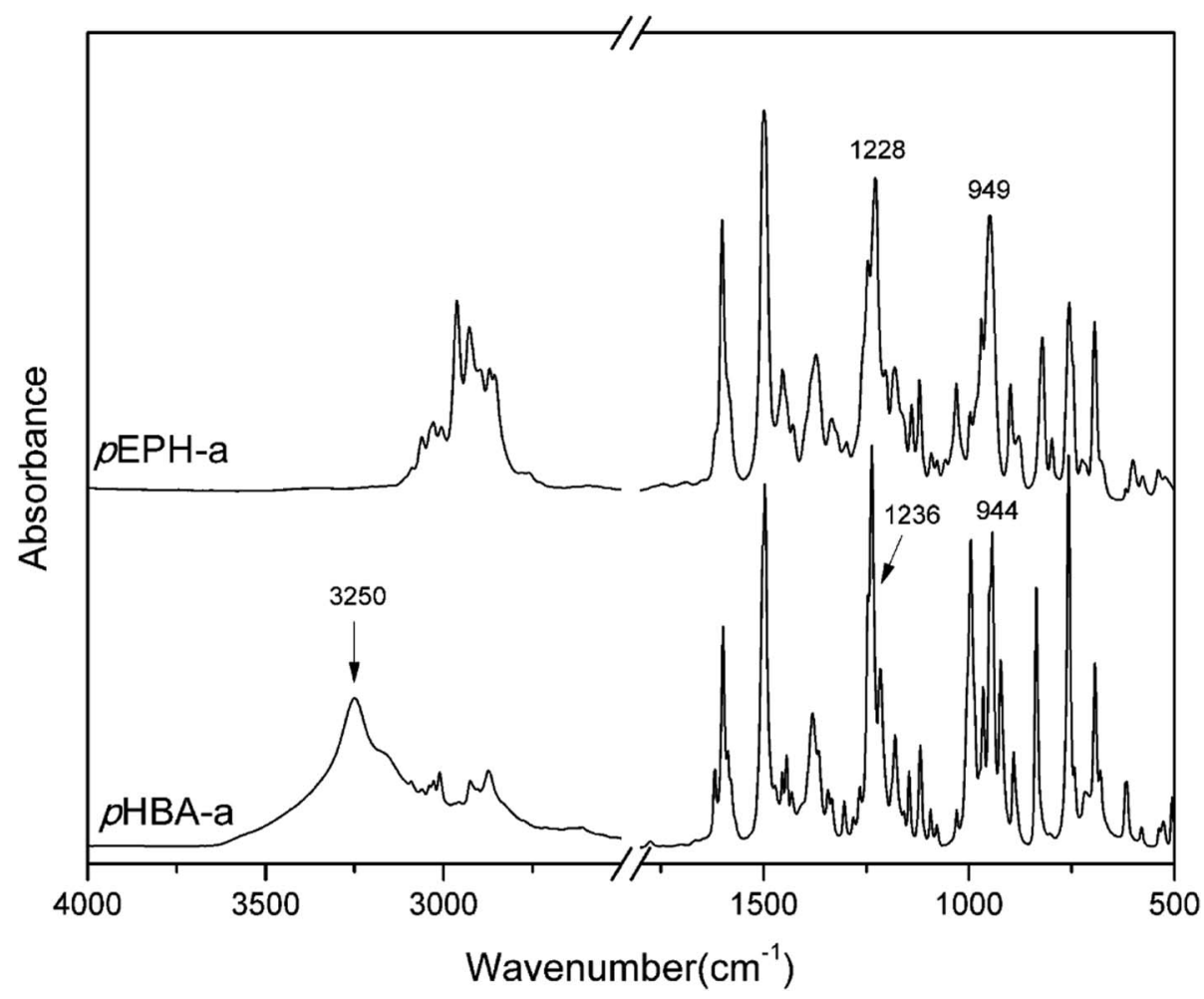

Fig. 3 FT-IR spectra of benzoxazine monomers. 


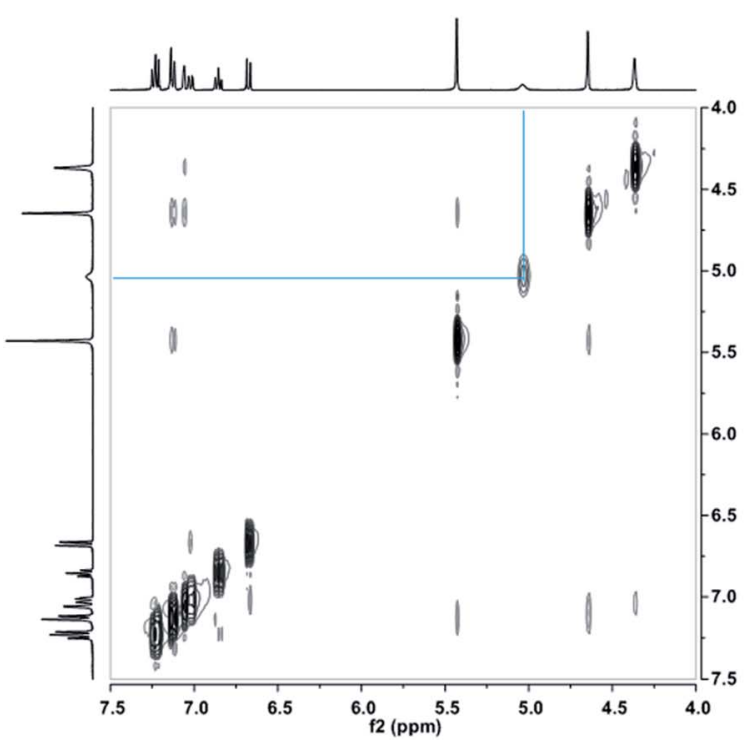

\section{NOE effect interaction observed}

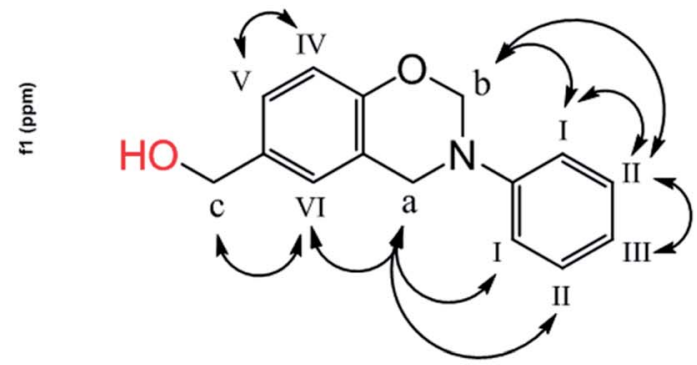

Fig. $42 \mathrm{D}{ }^{1} \mathrm{H}-{ }^{1} \mathrm{H}$ NOESY NMR spectra of pHBA-a in DMSO- $d_{6}$ at $25^{\circ} \mathrm{C}$ (left) and NOE interactions observed (right).

species, resulting in a stronger catalytic effect taking place. ${ }^{47}$ However, the methylol group has neither a strong electronwithdrawing nor acidic character. The existence of intermolecular hydrogen-bonding involving the methylol group and the oxazine ring seems to accelerate the ring-opening polymerization in an intermolecular manner. Besides, $p$ HBA-a shows an endothermic melting peak at $100{ }^{\circ} \mathrm{C}$ while the melting temperature of $p \mathrm{EPH}$-a centers at $44^{\circ} \mathrm{C}$. The appearance of $\mathrm{OH}$ in benzoxazine moiety significantly increases the melting temperature.

Fig. 5 also shows a comparison of TGA and DSC thermograms of benzoxazine monomers. As shown in Fig. 5a, the initial weight loss of $p \mathrm{EPH}$-a starts at $104^{\circ} \mathrm{C}$, and evaporation of an excessive amount, as high as $62.5 \%$ of monomer is observed before even starting polymerization, reflecting the nature of weak intermolecular interaction. The heat of melting value was 166.2 $\mathrm{J} \mathrm{g}^{-1}$ for $p$ HBA-a while a much lower heat value $\left(24.1 \mathrm{~J} \mathrm{~g}^{-1}\right)$ was found for $p \mathrm{EPH}-\mathrm{a}$, resulting in the easy evaporation of $p \mathrm{EPH}-\mathrm{a}$ during the thermal treatment. A further $\sim 35.2 \%$ of weight loss can be observed during the ring-opening polymerization at the range from $242{ }^{\circ} \mathrm{C}$ to $283{ }^{\circ} \mathrm{C}$, which is due to the cleavage of zwitterionic intermediate, forming very unstable phenolic species and $N$-methyleneaniline. ${ }^{23}$ The weight reduction at this high temperature might also come from the water evaporation due to the partial occurance of the traditional methylene bridge formation of methylol reacting with the benzene ring, and/or the condensation of methylol groups to form aliphatic ether bonds. However, the initial weight loss of $p$ HBA-a starts around $141{ }^{\circ} \mathrm{C}$, and the monomer evaporation has been significantly reduced only to $3.0 \%$ before starting polymerization due to the presence of methylol group. The weight loss during the polymerization of $p$ HBA-a is also much lower compared with that of $p \mathrm{EPH}-\mathrm{a}$. Furthermore, the dependence of viscosity of $p \mathrm{HBA}-\mathrm{a}$ on temperature was also investigated. In general, the required viscosity for resin transfer molding (RTM) processing technology is roughly below 1 Pa s at the processing temperature. Interestingly, the viscosity of $p$ HBA-a is less than $0.05 \mathrm{~Pa}$ s during 140 to $215^{\circ} \mathrm{C}$ at the heating rate of $5{ }^{\circ} \mathrm{C} \min ^{-1}$ as shown in Fig. 6, which exhibits the advantage of being monofunctional benzoxazine with very low
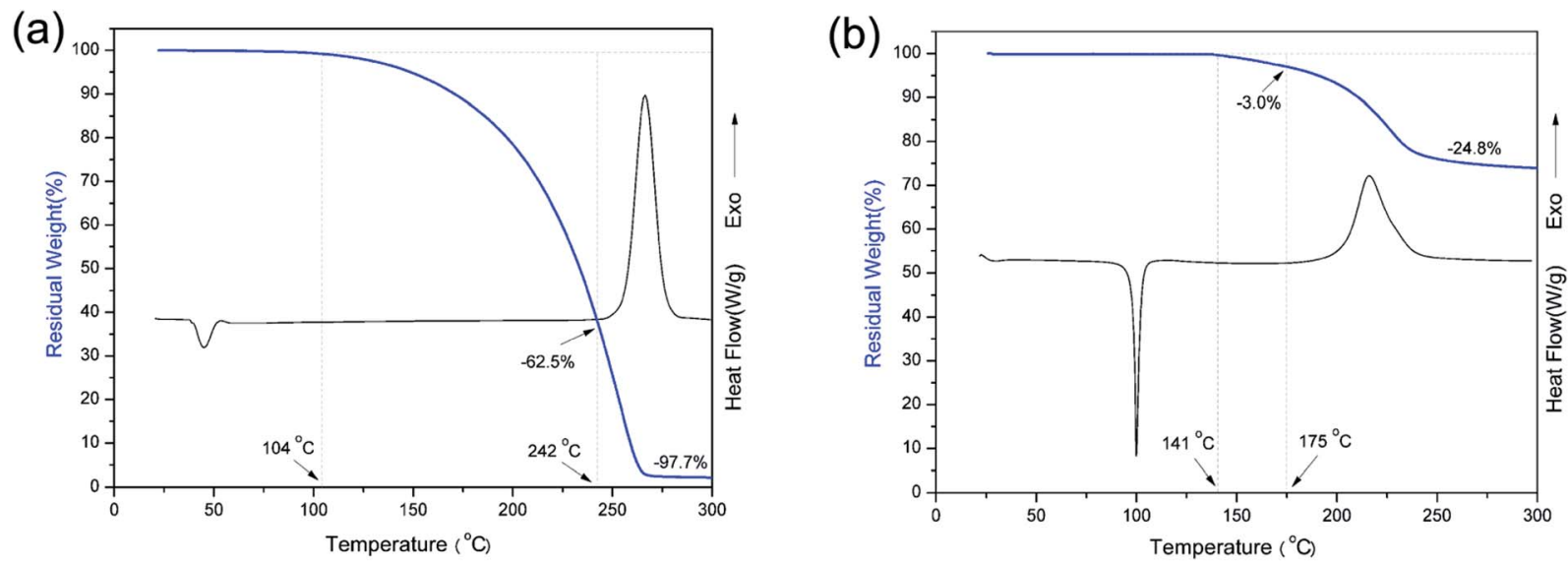

Fig. 5 TGA vs. DSC plots of benzoxazine monomers (heating rate: $10^{\circ} \mathrm{C} \mathrm{min}^{-1}$, under a $\mathrm{N}_{2}$ atmosphere): (a) $p \mathrm{EPH}-\mathrm{a}$ and (b) $p H B A-a$. 
viscosity. It should be cautioned that the transducer used for the viscosity measurement had the sensitivity limit in the vicinity of 0.1 $\mathrm{Pa}$ s and, therefore, this observed value should be taken as only the indication of low viscosity that easily satisfies the viscosity requirement for an RTM resin. All the result above highlights the advantage of the presence of methylol in benzoxazine moiety which is combined with a small monofunctional benzoxazine structure.

\section{Thermal properties of polybenzoxazines}

Fig. 7 shows the comparison of the DSC thermosgrams of polybenzoxazines. In general, the $T_{\mathrm{g}}$ of polybenzoxazines based on monofunctional benzoxazine monomers are much lower than the polybenzoxazines derived from difunctional benzoxazine monomers, which are due to the low crosslink density of monofunctional benzoxazines despite some expected reactivity on the aromatic ring of the phenolic and aniline moiety. ${ }^{8}$ As shown in Fig. 7, the $T_{\mathrm{g}}$ of poly $(p \mathrm{EPH}-\mathrm{a})$ is observed at $98{ }^{\circ} \mathrm{C}$, which is even lower than the polybenzoxazine based on PH-a (phenol and aniline based monobenzoxazine). ${ }^{48}$ The incorporation of ethyl functionality into benzoxazine decreases the rigidity of the molecule itself, resulting in a lower $T_{\mathrm{g}}$. However, poly $(p \mathrm{HBA}-\mathrm{a})$ shows a $T_{\mathrm{g}}$ as high as $261{ }^{\circ} \mathrm{C}$, which is unexpectedly higher than many other polybenzoxazines based on even difunctional benzoxazine monomers. ${ }^{12,49}$ An interesting observation for the glass transition behaviors is that the existence of great difference in $T_{\mathrm{g}}$ (as high as $163{ }^{\circ} \mathrm{C}$ ) between two polybenzoxazines, although only slight difference exists from the view point of their chemical structures.
DMA was applied to further confirm the glass transition temperature of polybenzoxazines. DMA samples of poly $(p \mathrm{EPH}-$ a) was difficult to prepare due to the very high amount $(97.7 \%)$ of monomer evaporation before and during the polymerization as shown in Fig. 5, thus only poly $(p H B A-a)$ was measured. The DMA results of poly $(p H B A-a)$ are shown in Fig. 8 for the storage modulus $\left(E^{\prime}\right)$, loss modulus $\left(E^{\prime \prime}\right)$ and $\tan \delta$. As shown in the figure, the $T_{\mathrm{g}}$ determined by the peak temperature of both $E^{\prime \prime}$ and $\tan \delta$ is as high as $274{ }^{\circ} \mathrm{C}$, which is in relatively good agreement with that measured by DSC at $261{ }^{\circ} \mathrm{C}$ in Fig. 6 . The significant improvement of $T_{\mathrm{g}}$ for poly $(p \mathrm{HBA}-\mathrm{a})$ seems to be attributed to the formation of rich intermolecular hydrogenbonding network endowed by methylol functionality along with phenolic Mannich bridge network. The weight reduction centered at $220{ }^{\circ} \mathrm{C}$ could also be partially attributed to this weight loss of water as a consequence of condensation reaction. As discussed earlier that some of the methylol groups might condense to form crosslinks based on the aliphatic ether group, which will aid in increasing the $T_{\mathrm{g}}$. Additional complication arises due to the possibility of the traditional methylene bridge formation in the phenolic resin by the aromatic methylol group reacting with the neighboring benzene rings. Further detailed analysis is needed to investigate this cause of weight reduction around $220{ }^{\circ} \mathrm{C}$ to be either as a result of aliphatic ether formation, methylene bridge formation, or degradation of the zwitterionic intermediates.

In order to better understand the effect of hydroxyl groups on the glass transition behavior of polybenzoxazines, coarsegrained dynamic Monte Carlo simulations were performed in this study. It has been well-known that the phenolic structure can be formed upon ring-opening polymerization of

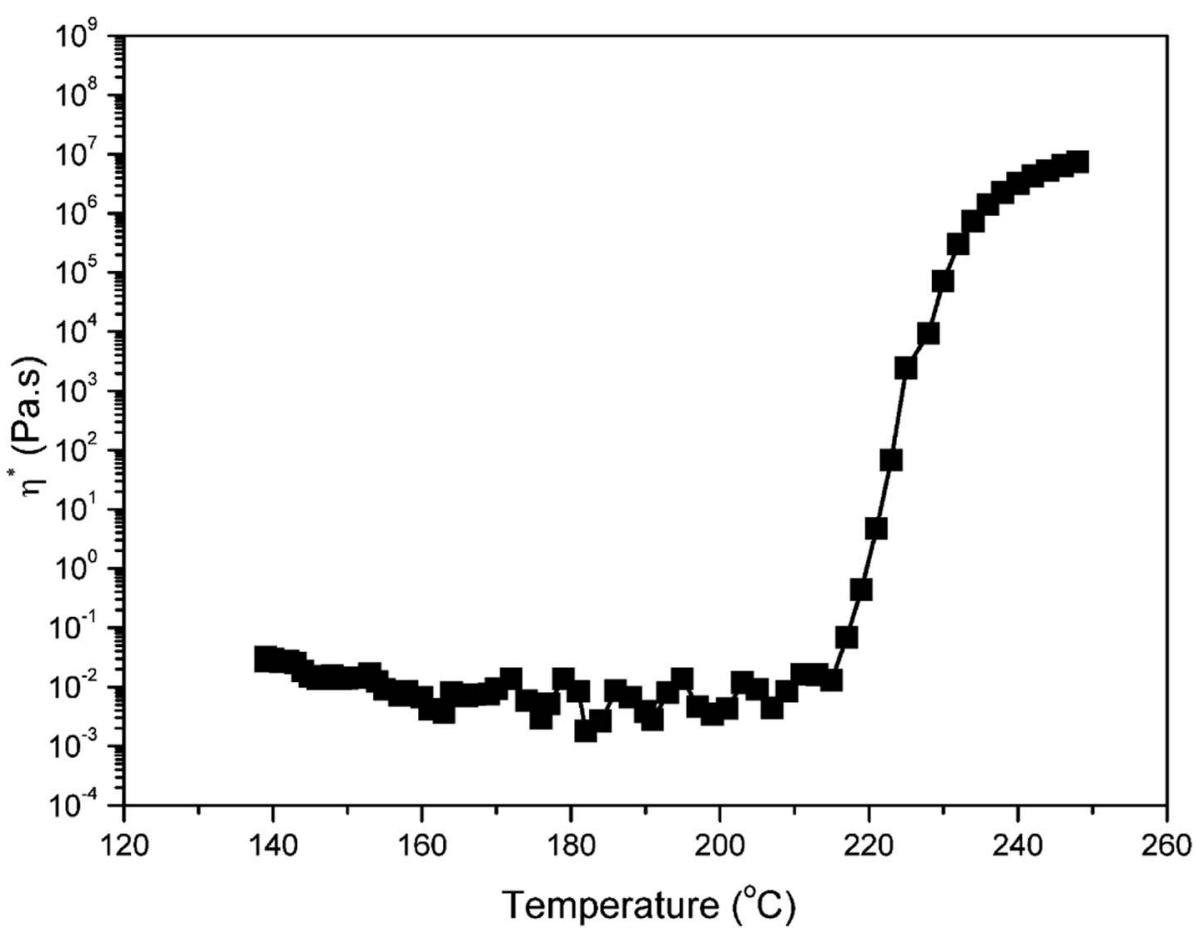

Fig. 6 Viscosity versus temperature of $p \mathrm{HBA}-\mathrm{a}$. 


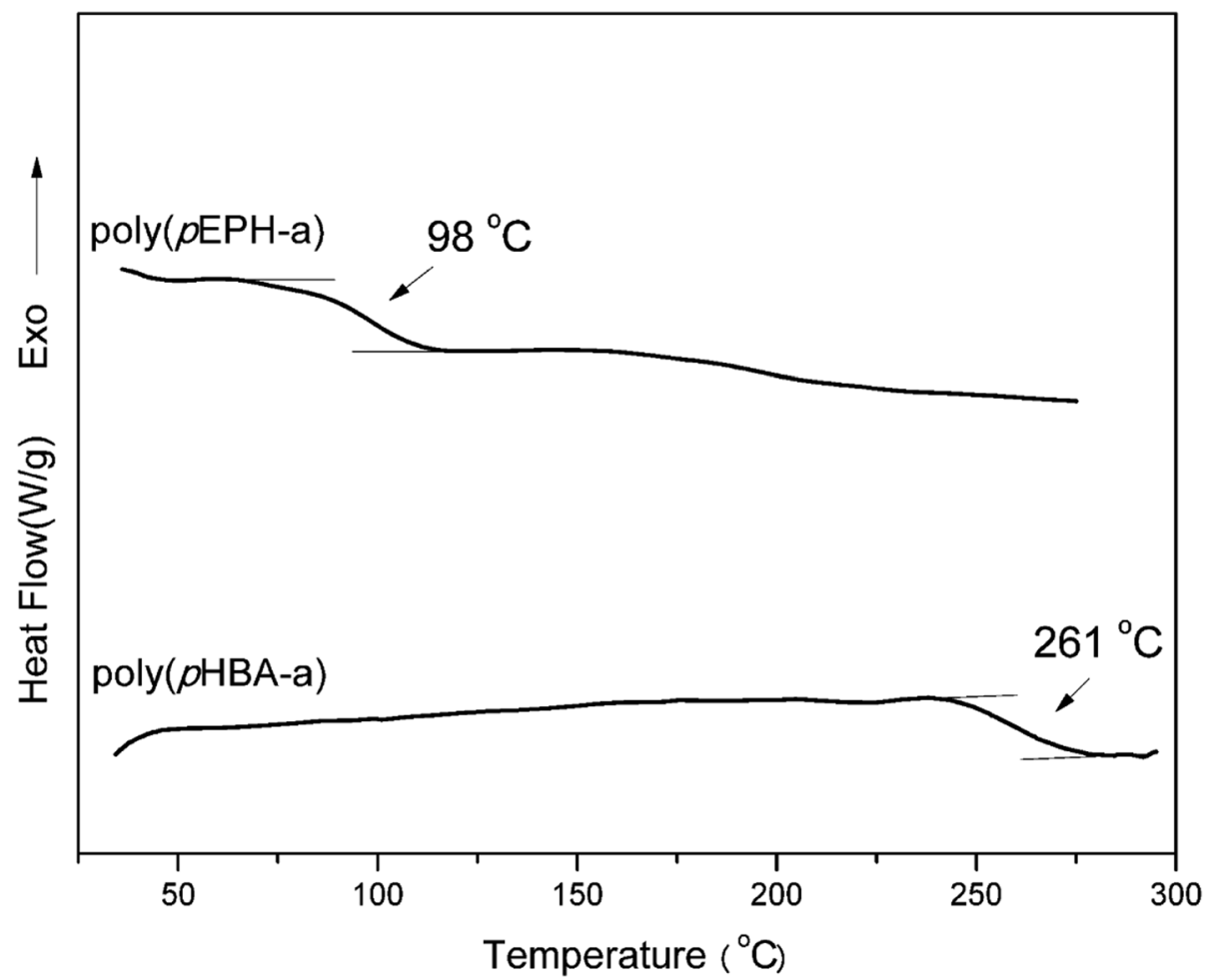

Fig. 7 DSC thermograms of poly $(p H B A-a)$ and poly $(p E P H-a)$.

benzoxazine, thus the ring-opening polymerization of $p$ HBAa and $p \mathrm{EPh}-\mathrm{a}$ can straightforwardly be described as shown in Scheme 2, neglecting the other possible crosslink reactions for simplicity. In addition, two model chains for poly $(p \mathrm{HBA}-\mathrm{a})$ and poly $(p \mathrm{EPH}-\mathrm{a})$ are also designed as shown in Scheme 2 (right part). Herein the red spheres denote the hydroxyl groups, while the blue spheres represent the remaining parts (benzene, methylene, benzyl amine and methyl, respectively) in both polybenzoxazines. Due to the demand for the simplicity of molecular simulations, the size difference between these groups was ignored.

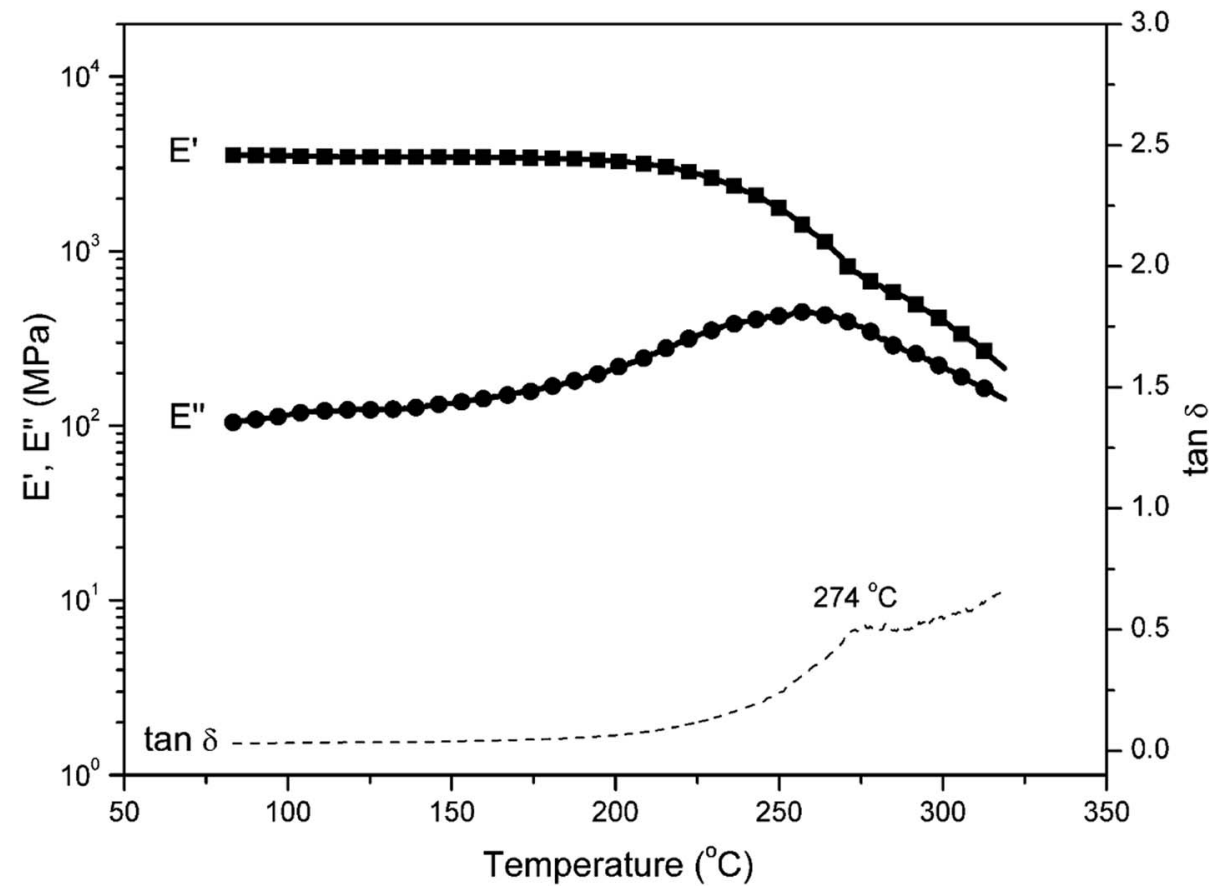

Fig. 8 Dynamic mechanical spectra of poly(pHBA-a). 
<smiles>OCc1ccc2c(c1)CN(c1ccccc1)CO2</smiles>

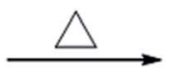

$p \mathrm{HBA}-\mathrm{a}$<smiles>CCc1ccc2c(c1)CN(c1ccccc1)CO2</smiles>

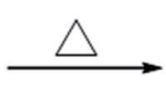

$p \mathrm{EPH}-\mathrm{a}$<smiles>CC(C)(C)c1cc(CO)cc(CN(c2ccccc2)C(C)(C)C)c1O</smiles>

$\operatorname{poly}(p \mathrm{HBA}-\mathrm{a})$<smiles>CCc1cc(CN(c2ccccc2)C(C)(C)C)c(O)c(C(C)(C)C)c1</smiles>

$\operatorname{poly}(p$ EPH-a)
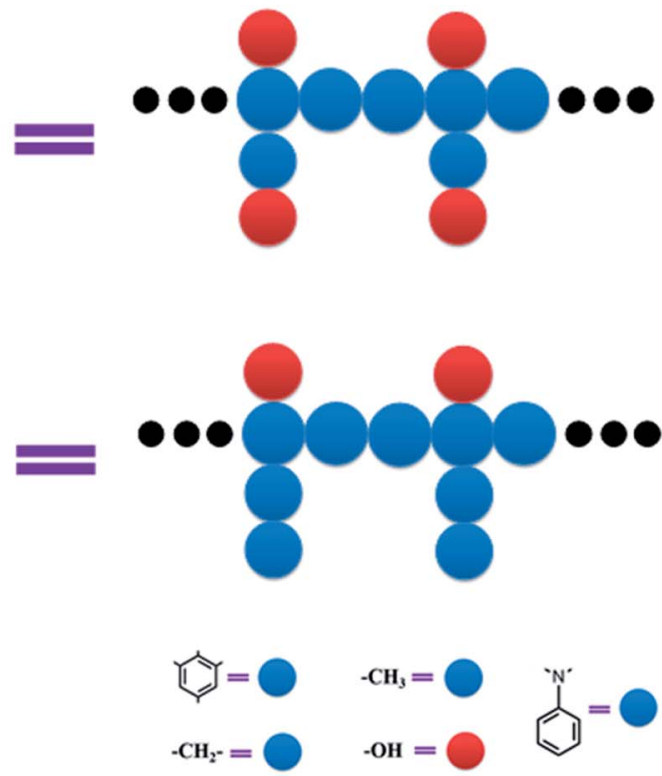

Scheme 2 Ring-opening polymerization of $p H B A-a$ and $p E P H-a$. The right part displays the schematic representation of model chains of polybenzoxazines.

One of the advantages of molecular simulations is that molecular motions can be tracked directly. Fig. 9 shows the evolutions of mean square displacements (MSDs) of segments during each cooling step:

$$
\begin{aligned}
\operatorname{MSD}= & \left\langle\left[\vec{r}_{\mathrm{i}}\left(t=100 \mathrm{MC} \text { cycles, } T^{*}\right)\right.\right. \\
& \left.\left.-\vec{r}_{\mathrm{i}}\left(t=0 \mathrm{MC} \text { cycles, } T^{*}\right)\right]^{2}\right\rangle
\end{aligned}
$$

where $\vec{r}_{\mathrm{i}}$ is the position of segments at the simulation time of $t$ and the temperature of $T^{*}$ (the reduced system temperature), and \langle\rangle denotes an average over all segments. As is well-known, MSD of segments is dominated by diffusion ability of segments, which is inversely proportional to viscosity. ${ }^{50}$ Therefore, we can use the changes of MSD of segments to reflect the molecular

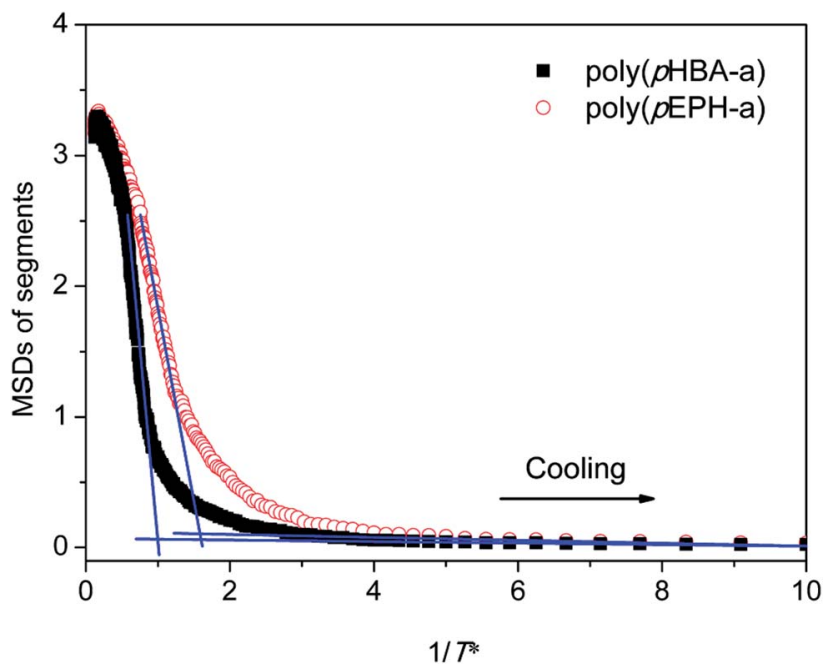

Fig. 9 The mean square displacements of segments during cooling process for poly $(p H B A-a)$ and poly $(p E P H-a)$, respectively. behavior of the polymer glass transition. As shown in Fig. 9, the MSDs of segments for both polybenzoxazines decrease at the initial stage during cooling. But the MSDs level off below a turning point, and the corresponding values are close to 0 at very low temperatures, indicating that segment motions have been completely frozen. In experiments, the glass transition is usually defined by the temperature at which relaxation time reaches $100 \mathrm{s.}^{51}$ However, the time scale of molecular simulations is much shorter (the simulation time unit is about $1 \mathrm{ps}$ ) compared with the experiments. Therefore, it is difficult for simulation time to reach the time scale of the experiments. In the current paper, we define the temperatures of the turning points in the MSD curves (namely, the crossing points of two extrapolation line in Fig. 8) as the glass transition temperatures. Again as seen in Fig. 9, poly $(p \mathrm{HBA}-\mathrm{a})$ exhibits much higher glass transition temperature $\left(T^{*}=1.05\right)$ than that of poly $(p \mathrm{EPH}-\mathrm{a})\left(T^{*}\right.$ $=0.65$ ), which is consistent with the experimental results shown above. Since poly $(p \mathrm{HBA}-\mathrm{a})$ contains methylol functionality, more proposed types of intermolecular hydrogen-bonding systems (Fig. 10) can be formed in polymeric network, which restricts the motions of polymer chains, resulting in the increase of its glass transition temperature. In the following sections, we further probe the details of the effects of the different segments on the polymer glass transition at the molecular scale.

Fig. 11 displays the evolutions of MSDs of different segments (the phenolic hydroxyl directly linked to the backbone; the hydroxyl from methylol groups on the side chains; and the remaining segments for poly $(p$ HBA-a), and the phenolic hydroxyl directly linked to the backbone, the methyl from ethyl groups on the side chains and the rest segments for poly $(p \mathrm{EPH}-\mathrm{a}))$ during cooling. As shown in Fig. 11, the value of the MSDs for both hydroxyl groups of poly $(p \mathrm{HBA}-\mathrm{a})$ is firstly dropped to 0 , indicating 


\section{$\operatorname{poly}(p H B A-a)$}

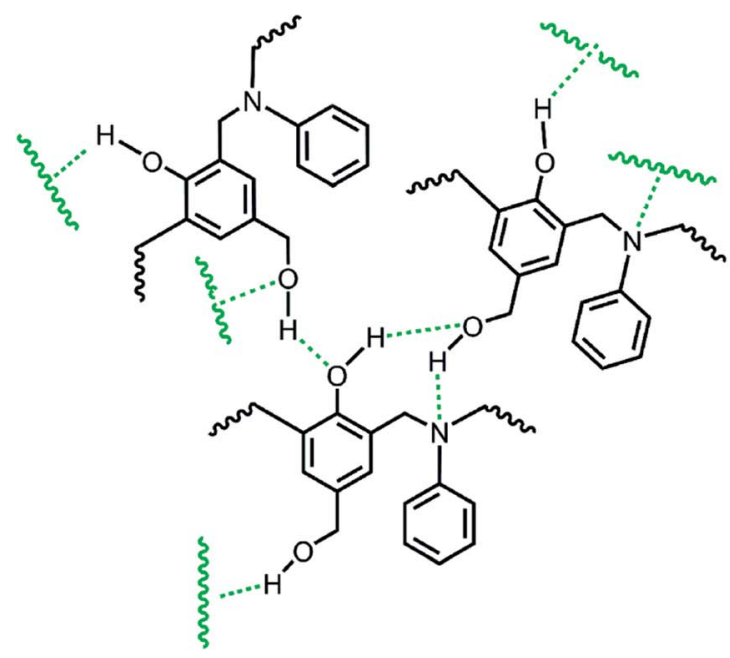

$\operatorname{poly}(p$ EPH-a)<smiles>CCc1cc(CC)c(O[C@@H]2CN(c3ccccc3)C[N+](CC)(c3ccccc3)Cc3cc(CC)cc(CC)c3O[C@H](CC)c3cc(CC)cc(CC)c32)c(CC)c1</smiles>

Fig. 10 Proposed intermolecular hydrogen-bonding interactions in poly $(p H B A-a)$ and poly $(p E P H-a)$.

that the hydroxyl groups in poly $(p \mathrm{HBA}-\mathrm{a})$ can be completely frozen prior to other segments in both polybenzoxazines. However, poly $(p \mathrm{EPH}-\mathrm{a})$ exhibits different changes of segmental mobility. The MSDs of the hydroxyl and the remaining segments reach 0 before that of the methyl. This result suggests that the only structural difference, the hydroxyl and methyl in parasubstitution of poly $(p \mathrm{HBA}-\mathrm{a})$ and $\operatorname{poly}(p \mathrm{EPH}-\mathrm{a})$, playing the opposite role for affecting the $T_{\mathrm{g}}$ of polybenzoxazine. The incorporation of methylol can significantly increases the $T_{\mathrm{g}}$ while ethyl decreases.

In addition, the intermolecular interactions formed among different types of hydroxyl groups in polybenzoxazines should also be considered. Fig. 12 depicts the variations of mixing parameters of the phenolic hydroxyl groups directly linked to the backbone for poly $(p$ HBA-a $)$ and poly $(p \mathrm{EPH}-\mathrm{a})$, and the hydroxyl from methylol

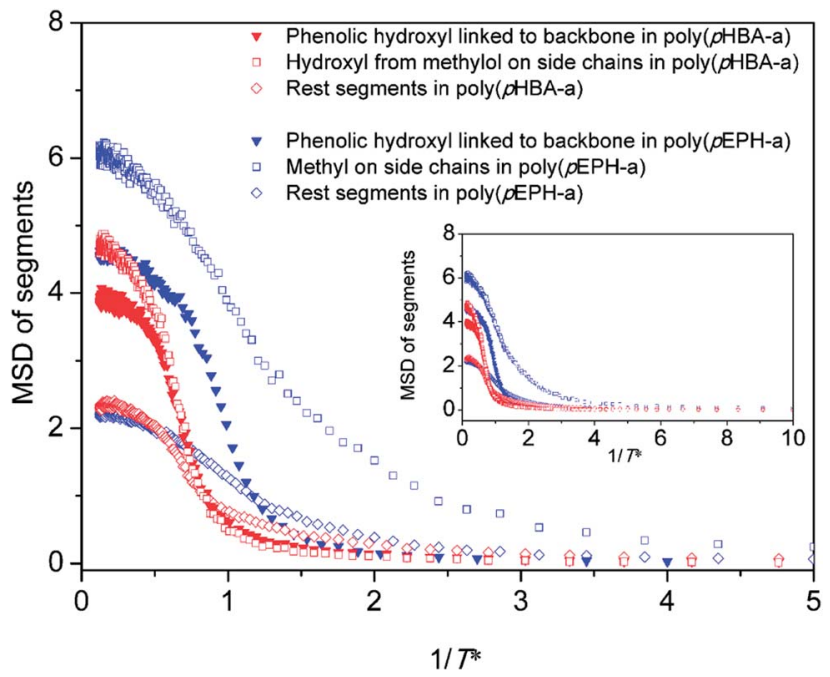

Fig. 11 The mean square displacements of different segments during cooling process for poly $(p H B A-a)$ and poly $(p E P H-a)$, respectively. groups on the side chains for $\operatorname{poly}(p \mathrm{HBA}-\mathrm{a})$, respectively. The mixing parameter of hydroxyl groups is defined as the mean fraction of neighboring sites of each hydroxyl occupied by other hydroxyl groups. It can be found that the mixing parameters of both types of hydroxyl groups of poly $(p \mathrm{HBA}-\mathrm{a})$ increase gradually during the glass transition process, indicating the local aggregation of the hydroxyl groups. In addition, the mixing parameters for the hydroxyl groups of poly $(p \mathrm{EPH}-\mathrm{a})$ also increase during the glass transition. However, for poly $(p H B A-a)$, the hydroxyl from methylol groups on side chains exhibits the higher plateau values compared with that directly linked to the backbone. For poly $(p \mathrm{EPH}-\mathrm{a})$, the corresponding plateau values are the lowest. Interestingly, the hydroxyl from methylol groups on side chains of poly $(p \mathrm{HBA}-\mathrm{a})$ possess the highest mobility and rather smaller steric

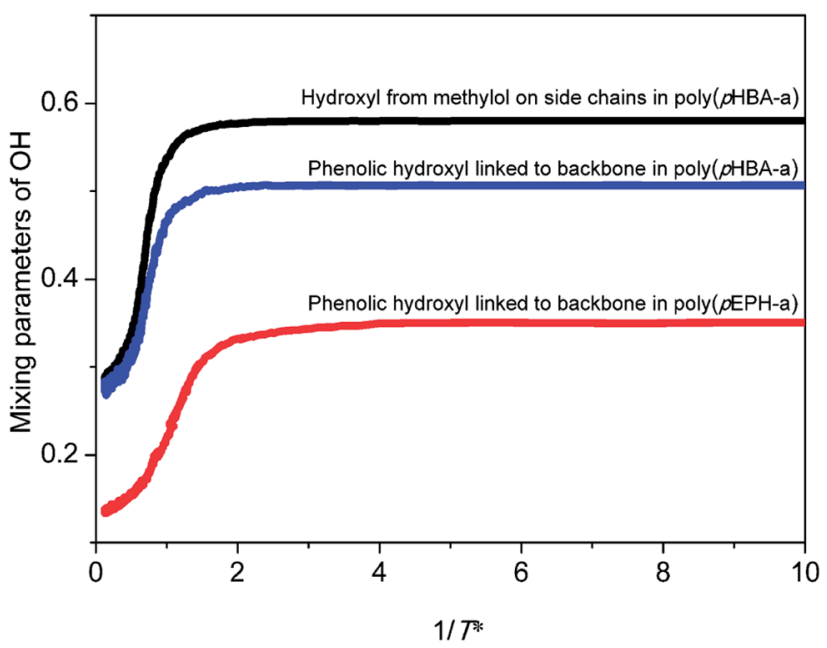

Fig. 12 Evolutions of mixing parameters of the phenolic hydroxyl groups directly linked to the backbone for poly $(p H B A-a)$ and poly $(p E P H-a)$, and the hydroxyl from methylol groups on the side chains for poly $(p H B A-a)$, respectively. 
hindrances at relatively high temperatures as demonstrated via the highest values of the MSDs as shown in Fig. 11, thus they are more prone to aggregate during cooling under the effect of the intermolecular interactions, resulting in the highest mixing parameters at low temperatures. This behavior is reflected on the curve being quickly reducing the MSD as the temperature is reduced than other groups, such as phenolic OHs, as shown in Fig. 11. However, due to the relatively high steric hindrances, the aggregation process of the phenolic hydroxyl groups directly linked to the backbone of poly( $p$ HBA-a) during cooling will somewhat hindered, leading to the lower values of mixing parameters than the methylol $\mathrm{OH}$ groups. Similarly, the phenolic hydroxyl groups directly linked to the backbone of poly $(p \mathrm{EPH}-\mathrm{a})$ have relatively low mobility as also demonstrated by the lower values of the MSDs in Fig. 10 than the phenolic $\mathrm{OH}$ groups of poly $(p \mathrm{HBA}-\mathrm{a})$. In the meantime, the adjacent main chain acts as large steric hindrances to block the aggregation of hydroxyl groups. As a result, it is most difficult for the hydroxyl groups in poly $(p \mathrm{EPH}-\mathrm{a})$ to aggregate in local regions, leading the lowest values of the mixing parameter among three different types of $\mathrm{OH}$ groups examined.

Fig. 13 directly displays the spatial distribution of the hydroxyl groups (the red spheres) in poly $(p \mathrm{HBA}-\mathrm{a})$ at two different temperatures $\left(T^{*}=8.0\right.$ and $T^{*}=0.5$; one above the glass transition temperature and the other below the glass transition temperature). It can be clearly seen in Fig. 13a that these hydroxyl groups distribute homogenously at $T^{*}=8.0$. However, at $T^{*}=0.5$, some local aggregation areas can be observed as shown in Fig. 13b, further demonstrating that the intermolecular interactions can drive the hydroxyl groups in poly $(p \mathrm{HBA}-\mathrm{a})$ to aggregate during cooling. Apparently, the hydroxyl groups of poly $(p \mathrm{HBA}-\mathrm{a})$ aggregate under the effects of the intermolecular hydrogen-bonding during glass transition process. The intermolecular interactions and the aggregation structures make the hydroxyl groups be frozen at a higher temperature compared with other segments. In addition, the freezing of the hydroxyl groups also restricts the motions of other segments. Thus, poly $(p H B A-a)$ exhibits a much higher glass transition temperature. However, it is much harder for the hydroxyl groups in $\operatorname{poly}(p \mathrm{EPH}-\mathrm{a})$ to aggregate during cooling, and thus they would be frozen at lower temperature compared with those in poly $(p$ HBA-a). Furthermore, the presence of the methyl on the side chains with relatively stronger mobility can also contribute to the decreasing of the glass transition temperature of poly $(p \mathrm{EPH}-\mathrm{a})$.

It is important to point out that the above dynamic Monte Carlo simulation examined the role of intermolecular hydrogen bonding of the various $\mathrm{OH}$ groups, disregarding the possible covalent bond formation. However, judging from the rubbery plateau not being completely horizontal, the covalent bond formation may not be complete. Slightly above the $T_{\mathrm{g}}$, weakening of the intermolecular hydrogen bonding is likely taking place which is reflected on the reduction of the $E^{\prime}$ values as the temperature increase. Therefore, evaluating the role of intermolecular hydrogen bonding is essential in understanding the properties of the polybenzoxazines of current study.

Despite this weakening of the interaction in the rubbery plateau, the $E^{\prime}$ at $T_{\mathrm{g}}+50{ }^{\circ} \mathrm{C}$ is much greater than the crosslinked polybenzoxazine derived from bisphenol A and aniline, which is usually abbreviated in the literature as BA-a. The $\mathrm{G}^{\prime}$ of poly(Ba-a) at $T_{\mathrm{g}}+50{ }^{\circ} \mathrm{C}$ was reported to be $4.5 \mathrm{MPa} .{ }^{14}$ Considering that the Poisson's ratio of polybenzoxazines at this temperature is not far from 0.50 , it is equivalent to around $E^{\prime}=10 \mathrm{MPa}$. The $E^{\prime}$ of poly $(p$ HBA-a) under current study is $30 \mathrm{MPa}$, indicating that this mono-oxazine benzoxazine has unexpectedly higher effective crosslink density than bisoxazine like the one derived from BA-a.

TGA was used to study the thermal stability of polybenzoxazines and results are shown in Fig. 14. A summary of the main thermal properties, $T_{\mathrm{d} 5}$ and $T_{\mathrm{d} 10}$, defined as the temperatures at which a weight loss of 5 and $10 \%$, respectively, occurred, and char yield, defined as the residual weight at $800{ }^{\circ} \mathrm{C}$ under $\mathrm{N}_{2}$ atmosphere, are presented in Table 1.

For polybenzoxazines based on monofunctional benzoxazine monomers, the initial decomposition temperatures are lower

\section{(a)}

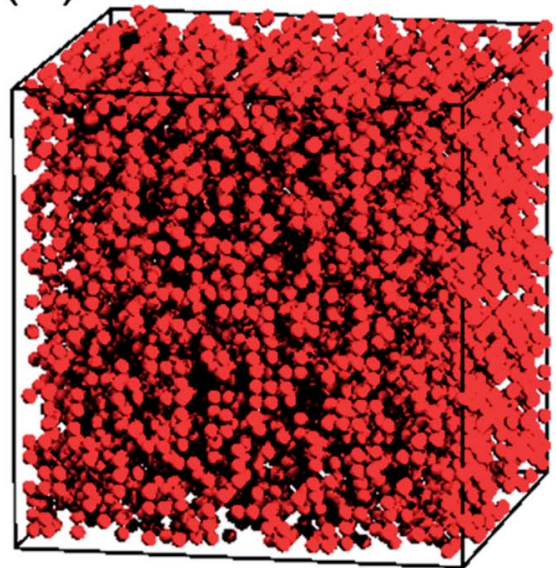

(b)

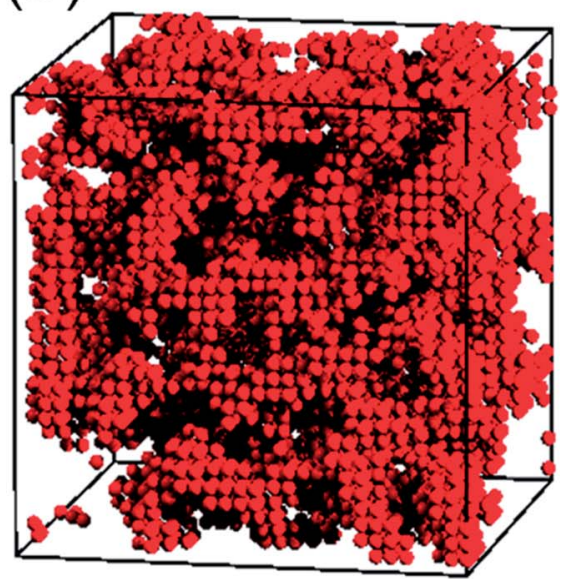

Fig. 13 Snapshots for the spatial distribution of the hydroxyl groups (the red spheres) in $t$ poly $(p H B A-a)$ at two different temperatures $(T *=8.0$ and $\left.T^{*}=0.5\right)$. 


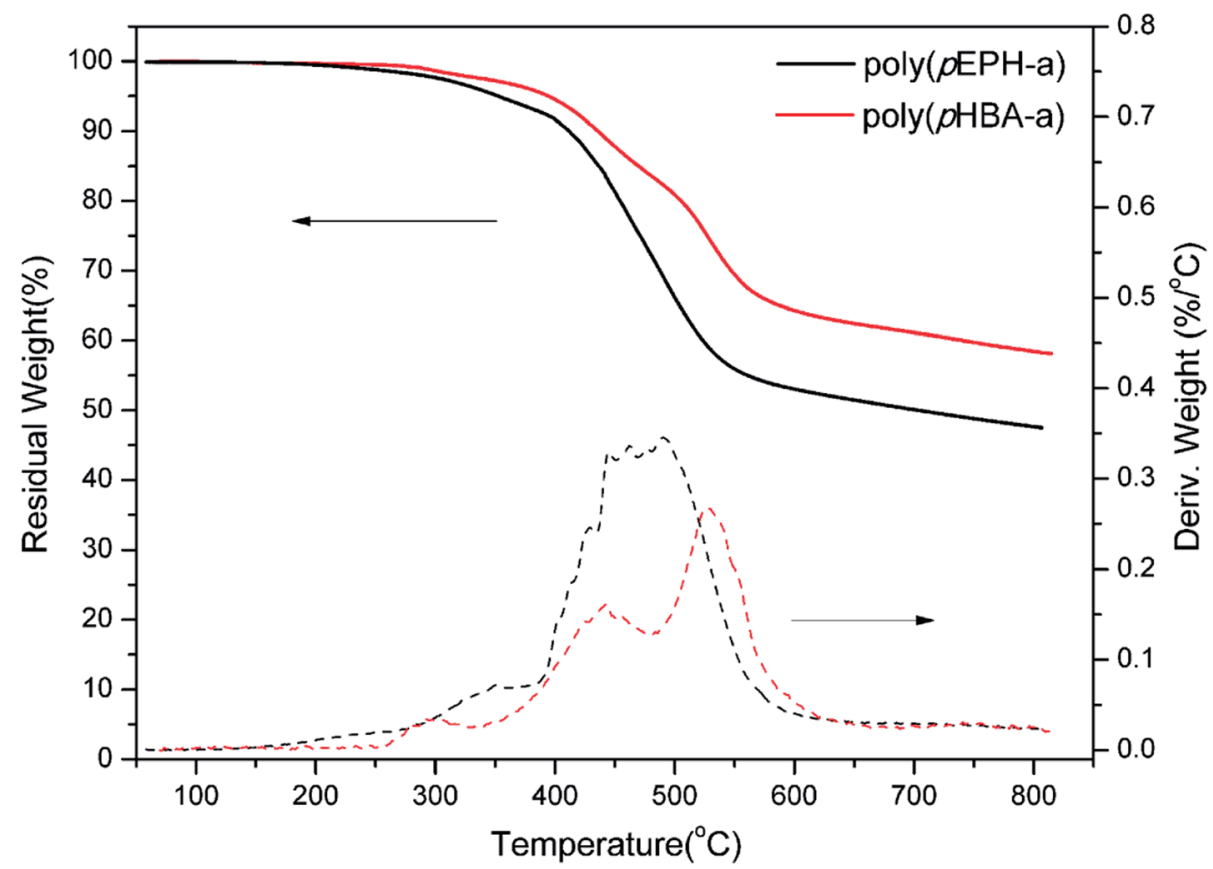

Fig. 14 Thermogravimetric analysis of poly $(p H B A-a)$ and poly $(p E P H-a)$.

Table 1 Summary of TGA thermogram results

\begin{tabular}{|c|c|c|c|c|c|}
\hline \multirow[b]{2}{*}{ Sample } & \multicolumn{2}{|c|}{$T_{\mathrm{g}}\left({ }^{\circ} \mathrm{C}\right)$} & \multicolumn{3}{|c|}{ TGA $\left(\mathrm{N}_{2}\right)$} \\
\hline & DSC & DMA $(\tan \delta)$ & $T_{\mathrm{d} 5}\left({ }^{\circ} \mathrm{C}\right)$ & $T_{\mathrm{d} 10}\left({ }^{\circ} \mathrm{C}\right)$ & $(\%)$ \\
\hline $\operatorname{poly}(p$ EPH-a) & 98 & - & 351 & 404 & 47 \\
\hline $\operatorname{poly}(p$ HBA-a) & 261 & 274 & 395 & 436 & 60 \\
\hline
\end{tabular}

than for the polybenzoxazines derived from difunctional benzoxazine monomers. The initial degradation of monofunctional benzoxazine based polybenzoxazines are mostly taken place from the terminal Schiff base and secondary amides as structural defects. ${ }^{52}$ However, the decomposition temperatures of poly $(p H B A-a)$ reflected on the $T_{\mathrm{d} 5}$ and $T_{\mathrm{d} 10}$ are 395 and $436{ }^{\circ} \mathrm{C}$, respectively, which are significantly higher than poly $(p \mathrm{EPH}-\mathrm{a})$. Moreover, poly $(p$ HBA-a $)$ presents a char yield of $60 \%$ at $800{ }^{\circ} \mathrm{C}$, which is considerably higher than that of poly $(p \mathrm{EPH}-\mathrm{a})$ (47\%). TGA results suggest an enhanced thermal stability of the polybenzoxazines with additional hydroxyls by incorporation of methylol functionality.

\section{Conclusions}

Two monofunctional benzoxazines have been synthesized by introducing methylol and ethyl group, respectively, as part of the monomers. These two monomers were designed in order to study the influence of hydroxyl groups on the thermal properties of polybenzoxazines. As a result, the $T_{\mathrm{g}}$ of polybenzoxazine with methylol functionality was found to be unexpectedly higher than its counterpart without additional hydroxyls. Dynamic Monte Carlo simulations were applied to fundamentally study the structure-property relationship between molecular interactions and thermal properties of polybenzoxazines. The combination of molecular design with experiments and simulations clearly demonstrated that the hydroxyl functionality in the monomer serves two roles to improve the remarkable thermal properties of polybenzoxazines, such as hydrogen-bonding sites and additional crosslinking sites (phenolic Mannich bridge network, aliphatic ether linkages).

\section{Conflicts of interest}

There are no conficts to declare.

\section{Acknowledgements}

We thank the financial support of the National Natural Science Foundation of China (NSFC) (Nos. 51603093 and 21404050) and the Jiangsu Provincial Science and Technology Agency (No. BK20160515).

\section{References}

1 X. Li, Y. Xia, W. Xu, Q. Ran and Y. Gu, Polym. Chem., 2012, 3, 1629-1633.

2 H. Ishida and T. Aaga, Handbook of Benzoxazine Resins, Elsevier, Amsterdam, 2011.

$3 \mathrm{H}$. Ishida and P. Froimowicz, Advanced and Emerging Polybenzoxazine Science and Technology, Elsevier, Amsterdam, 2017.

4 C. P. R. Nair, Prog. Polym. Sci., 2004, 29, 401-498. 
5 N. N. Ghosh, B. Kiskan and Y. Yagci, Prog. Polym. Sci., 2007, 32, 1344-1391.

6 T. Takeichi, T. Kawauchi and T. Agag, Polym. J., 2008, 40, 1121-1131.

7 S. Ohashi, J. Kilbane, T. Heyl and H. Ishida, Macromolecules, 2015, 48, 8412-8417.

8 K. Zhang, J. Liu, S. Ohashi, X. Liu, Z. Han and H. Ishida, J. Polym. Sci., Part A: Polym. Chem., 2015, 53, 1330-1338.

9 K. Zhang, J. Liu and H. Ishida, Macromolecules, 2014, 47, 8674-8681.

10 H. Ishida and H. Y. Low, Macromolecules, 1997, 30, 10991106.

11 M. W. Wang, C. H. Lin and T. Y. Juang, Macromolecules, 2013, 46, 8853-8863.

12 J. Wu, Y. Xi, G. T. McCandless, Y. Xie, R. Menon, Y. Patel, D. J. Yang, S. T. lacono and B. M. Novak, Macromolecules, 2015, 48, 6087-6095.

13 K. Zhang, L. Han, P. Froimowicz and H. Ishida, Macromolecules, 2017, 50, 6552-6560.

14 H. Ishida and D. J. Allen, J. Polym. Sci., Part B: Polym. Phys., 1996, 34, 1019-1030.

15 H. Yan, C. Sun, Z. Fang, X. Liu, J. Zhu and H. Wang, Polymer, 2016, 97, 418-427.

16 T. Agag, C. R. Arza, F. H. J. Maurer and H. Ishida, Macromolecules, 2010, 43, 2748-2758.

17 K. Zhang and H. Ishida, Polym. Chem., 2015, 6, 2541-2550.

18 S. N. Kolanadiyil, J. Bijwe and I. K. Varma, React. Funct. Polym., 2013, 73, 1544-1552.

19 M. Ergin, B. Kiskan, B. Gacal and Y. Yagci, Macromolecules, 2007, 40, 4724-4727.

20 T. Agag and T. Takeichi, Macromolecules, 2001, 34, 72577263.

21 H. Qi, H. Ren, G. Pan, Y. Zhuang, F. Huang and L. Du, Polym. Adv. Technol., 2009, 20, 268-272.

22 Y. L. Liu and C. I. Chou, J. Polym. Sci., Part A: Polym. Chem., 2005, 43, 5267-5282.

23 N. K. Sini and T. Endo, Macromolecules, 2016, 49, 8466-8478.

24 B. Kiskan, B. Koz and Y. Yagci, J. Polym. Sci., Part A: Polym. Chem., 2009, 47, 6955-6961.

25 R. Kudoh, A. Sudo and T. Endo, Macromolecules, 2010, 43, 1185-1187.

26 M. Baqar, T. Agag, H. Ishida and S. Qutubuddin, React. Funct. Polym., 2013, 73, 360-368.

27 Y. C. Su, W. C. Chen, K. I. Ou and F. C. Chang, Polymer, 2005, 46, 3758-3766.

28 L. Jin, T. Agag, Y. Yagci and H. Ishida, Macromolecules, 2011, 44, 767-772.

29 M. Baqar, T. Agag, H. Ishida and S. Qutubuddin, Polymer, 2011, 52, 307-317.
30 M. Baqar, T. Agag, H. Ishida and S. Qutubuddin, J. Polym. Sci., Part A: Polym. Chem., 2012, 50, 2275-2285.

31 M. Baqar, T. Agag, R. Huang, J. Maia, S. Qutubuddin and H. Ishida, Macromolecules, 2012, 45, 8119-8125.

32 K. Zhang, P. Froimowicz, L. Han and H. Ishida, J. Polym. Sci., Part A: Polym. Chem., 2016, 54, 3635-3642.

33 K. Zhang, L. Han, P. Froimowicz and H. Ishida, React. Funct. Polym., 2017, DOI: 10.1016/j.reactfunctpolym.2017.06.017.

34 W. B. Hu and D. Frenkel, Adv. Polym. Sci., 2005, 191, 1-35.

35 Y. J. Nie, Z. Z. Gu, Q. Zhou, Y. Wei, T. F. Hao, Y. Liu, R. J. Liu and Z. P. Zhou, J. Phys. Chem. B, 2017, 121, 6685-6690.

36 Y. J. Nie, T. F. Hao, Z. Z. Gu, Y. Wang, Y. Liu, D. Zhang, Y. Wei, S. J. Li and Z. P. Zhou, J. Phys. Chem. B, 2017, 121, 1426-1437.

37 Q. Y. Tang, W. B. Hu and S. Napolitano, Phys. Rev. Lett., 2014, 112, 148306.

38 Q. Y. Tang and W. B. Hu, Phys. Chem. Chem. Phys., 2013, 15, 20679-20690.

39 B. Lobe, J. Baschnagel and K. Binder, Macromolecules, 1994, 27, 3658-3665.

40 T. S. Jain and J. J. de Pablo, Macromolecules, 2002, 35, 21672176.

41 Y. J. Nie, X. B. Ye, Z. P. Zhou, W. M. Yang and L. Tao, J. Chem. Phys., 2014, 141, 074901.

42 X. B. Ye, Z. P. Zhou, Y. J. Nie, P. Ma, T. F. Hao, W. M. Yang and H. F. Lu, Macromol. Theory Simul., 2016, 25, 9-15.

43 Y. J. Nie, X. B. Ye, X. Y. Qiu, T. F. Hao, R. J. Liu, Z. P. Zhou, Y. Wei, Z. Z. Gu, W. M. Yang and S. J. Li, Comput. Mater. Sci., 2018, 142C, 200-205.

44 Y. J. Nie, Z. P. Zhou, T. F. Hao, X. B. Ye and W. M. Yang, Macromol. Theory Simul., 2016, 25, 187-195.

45 J. Dunkers and H. Ishida, Spectrochim. Acta, Part A, 1995, 51, 1061-1074.

46 L. Han, D. Iguchi, P. Gil, T. R. Heyl, V. M. Sedwick, C. R. Arza, S. Ohashi, D. J. Lacks and H. Ishida, J. Phys. Chem. A, 2017, 121, 6269-6282.

47 R. Andreu, J. A. Reina and J. C. Ronda, J. Polym. Sci., Part A: Polym. Chem., 2008, 46, 3353-3366.

48 L. Han, M. L. Salum, K. Zhang, P. Froimowicz and H. Ishida, J. Polym. Sci., Part A: Polym. Chem., 2017, 55, 3434-3445.

49 J. Wang, M. Q. Wu, W. B. Liu, S. W. Yang, J. W. Bai, Q. Q. Ding and Y. Li, Eur. Polym. J., 2010, 46, 1024-1031.

50 G. K. Batchelor, An Introduction to Fluid Dynamics, Cambridge University Press, 1973.

51 P. Z. Hanakata, J. F. Douglas and F. W. Starr, J. Chem. Phys., 2012, 137, 244901.

52 I. Hamerton, S. Thompson, B. J. Howlin and C. A. Stone, Macromolecules, 2013, 46, 7605-7615. 